ORIGINAL ARTICLE

\title{
The impact of involvement of biomedical scientists in specimen dissection and selection of blocks for histopathology: a study of time benefits and specimen handling quality in Ayrshire and Arran area laboratory
}

\author{
F R Duthie, E R Nairn, A W Milne, V McTaggart, D Topping
}

J Clin Pathol 2004;57:27-32

See end of article for authors' affiliations

Correspondence to:

Dr F R Duthie, Department of Pathology, North

Glasgow University NHS

Trust, Glasgow Royal

Infirmary, 84 Castle Street,

Glasgow G4, UK;

fraserduthie@yahoo.co.uk

Accepted for publication 4 August 2003

\begin{abstract}
Aims: To assess possible time benefits of specimen dissection by biomedical scientists (BMSs) and the quality of specimen handling by BMSs, in a department where BMSs trim those specimens requiring simple descriptions, from which standard blocks are taken.

Methods: Specimen handling by BMSs and consultant pathologists was compared. Time taken for each specimen trimmed was recorded prospectively. To determine specimen handling quality, adherence to dissection standard operating procedures (SOPs) was assessed by recording retrospectively whether or not each action in the SOP had been performed. Information on subsequently required extra levels or blocks was recorded.

Results: Analysis of data from 672 specimens trimmed by consultants showed that any given action in the SOPs was performed on average on $60.2 \%$ of applicable/assessable specimens; for 660 similar specimens trimmed by BMSs, each action was performed on average on $80.1 \%$ of specimens. Of the specimens where data on extra blocks were recorded, extra blocks were required in $3 \%$ of those trimmed by pathologists and in $4 \%$ of those trimmed by BMSs. Extra levels were required in $12 \%$ of those trimmed by pathologists and in $16 \%$ of those trimmed by BMSs. BMS trimming saves 16 hours of consultant time each month. The difference between pathologists and BMSs in time for each specimen trimmed is negligible.

Conclusions: The advantages of increased adherence to trimming SOPs and saving consultant time outweigh the relatively small number of extra blocks and levels required when BMSs trim. There is no reduction in quality of dissection.
\end{abstract}

$\mathrm{T}$ here has been controversy in the past regarding the involvement of biomedical scientists (BMSs) in surgical specimen examination and dissection, ${ }^{12}$ but the Royal College of Pathologists has recently issued guidance on this subject and has completed 12 pilot studies (results awaited). This is not a new initiative because pathologist's assistants (PAs) in the USA ${ }^{3}$ and BMSs in the UK have been performing the surgical cut up for over 45 years. ${ }^{45}$ Ayrshire and Arran area laboratory introduced BMS specimen dissection in 1999 when faced with a shortage of medical staff, and was one of the college pilot sites. The department has six histopathologists and one cytopathologist, with 17136 requests, 21408 specimens, 44443 blocks, and 92000 slides for surgical pathology in the year 2001. The purpose of our study was to attempt to measure the benefits from the introduction of BMS staff in the surgical cut up.

Because the manpower shortage among pathologists is continuing and other departments are considering introducing BMS cut ups, it seemed prudent to assess the quantitative and qualitative effects of having BMS trimming within our department. In our laboratory, specimens are classified into four categories of complexity (table 1). Those specimens that need only to be transferred into a cassette are classed as category A and can be handled by any qualified BMS, as is common practice in many pathology laboratories in the UK. Those that require a relatively simple dissection and description, and for which standard blocks could be taken, are classified as category B and are deemed suitable to be trimmed by an appropriately trained BMS. It is the impact of the trimming of these category B specimens by BMSs that our study will investigate. The remainder of the specimens (category $\mathrm{C}$ and category $\mathrm{D}$ ) are trimmed by pathologists, but category $\mathrm{C}$ specimens are relatively simple, and it is anticipated that they will be handled by BMSs in the near future.

\begin{abstract}
"Because the manpower shortage among pathologists is continuing and other departments are considering introducing biomedical scientist (BMS) cut ups, it seemed prudent to assess the quantitative and qualitative effects of having BMS trimming within our department"
\end{abstract}

To do this we assessed the impact of BMS cut ups on the pathologists' time by recording-prospectively, over a one month period-the time spent handling different categories of specimens for all staff involved in specimen handling. We compared the quality of category $\mathrm{B}$ specimen trimming between BMSs and consultant pathologists by comparing the adherence to departmental specimen handling protocols for such specimens in November 1997 (when all specimens were trimmed by consultant pathologists) and November 2001 (by which time category B specimens were trimmed by BMSs). There were no trainee pathologists in the department in either of these two months.

Abbreviations: BMS, biomedical scientist; PA, pathologist's assistant; $\mathrm{SOP}$, standard operating procedure 
Table 1 Routinely received surgical specimens, listed by category according to complexity and grade of staff handling specimens

\begin{tabular}{|c|c|c|c|}
\hline $\begin{array}{l}\text { Category } \mathrm{A} \\
\text { No trimming required }\end{array}$ & $\begin{array}{l}\text { Category B } \\
\text { Trimmed by BMS }\end{array}$ & $\begin{array}{l}\text { Category C } \\
\text { Trimmed by medical staff } \\
\text { (possibly by BMS in future) }\end{array}$ & $\begin{array}{l}\text { Category } D \\
\text { Trimmed by medical staff }\end{array}$ \\
\hline $\begin{array}{l}\text { (1) Aural polyp } \\
\text { (2) Bladder curetting } \\
\text { (3) Bone biopsy, no trimming } \\
\text { (4) Bone marrow trephine } \\
\text { (5) Cell block } \\
\text { (6) Cervical biopsy } \\
\text { (7) Cervical polyp } \\
\text { (8) Conjunctival biopsy } \\
\text { (9) Endoscopic biopsy } \\
\text { (10) Incisional skin biopsy } \\
\text { (11) Needle biopsy } \\
\text { (12) Prostate TUR } \\
\text { (13) Small colonic polyp } \\
\text { (14) Synovial biopsy } \\
\text { (15) Temporal artery } \\
\text { (16) Testicular biopsy } \\
\text { (17) Uterine curetting } \\
\text { (18) Vocal cord biopsy }\end{array}$ & $\begin{array}{l}\text { (1) Appendix } \\
\text { (2) Appendix testis } \\
\text { (3) Benign ovarian cyst (cystectomy) } \\
\text { (4) Benign skin biopsy } \\
\text { (5) Cervix (Manchester repair) } \\
\text { (6) Cone biopsy } \\
\text { (7) Dental cyst } \\
\text { (8) Endometrial polyp } \\
\text { (9) Epididymal cyst } \\
\text { (10) Fallopian tube } \\
\text { (11) Fallopian tube (ectopic } \\
\text { pregnancies) } \\
\text { (12) Femoral head } \\
\text { (13) Foreskin } \\
\text { (14) Gall bladder } \\
\text { (15) Ganglion } \\
\text { (16) Large colonic polyp } \\
\text { (17) Lipomata } \\
\text { (18) Lymph node } \\
\text { (19) Malignant skin biopsy } \\
\text { (20) Meckel's diverticulum } \\
\text { (21) Molar pregnancy } \\
\text { (22) Nasal polyp } \\
\text { (23) Nipple biopsy } \\
\text { (24) Perianal wart } \\
\text { (25) Products of conception } \\
\text { (26) Cysts (all cysts, not solid) } \\
\text { (27) Abscess or sinus tract (including } \\
\text { pilonidal sinus) } \\
\text { (28) Small ovary } \\
\text { (29) Tonsil } \\
\text { (30) Uterine fibroid } \\
\text { (31) Uterus } \pm \text { cervix (negative history) } \\
\text { (32) Vas deferens }\end{array}$ & $\begin{array}{l}\text { (1) Benign salivary gland } \\
\text { (2) Brachial cyst } \\
\text { (3) Breast duct excision } \\
\text { (4) Diverticular disease bowel } \\
\text { (5) Gastrectomy (benign ulcer) } \\
\text { (6) Gastrointestinal resection } \\
\text { (non-neoplastic) } \\
\text { (7) Jejunal biopsy (capsule) } \\
\text { (8) Ovarian cyst } \\
\text { (9) Parathyroid } \\
\text { (10) Placenta } \\
\text { (11) Skin of eyelid and ear } \\
\text { (12) Small breast biopsy } \\
\text { (13) Soft tissue tumour (small) } \\
\text { (14) Solid skin lump } \\
\text { (15) Thyroid } \\
\text { (16) Spleen } \\
\text { (17) Stoma } \\
\text { (18) Suprapubic prostatectomy } \\
\text { (19) Testis (simple) } \\
\text { (20) Thyroglossal duct cyst } \\
\text { (21) Uterus and cervix } \\
\text { (positive history; CIN) }\end{array}$ & $\begin{array}{l}\text { (1) Bone tumour } \\
\text { (2) Breast localisation } \\
\text { (3) Colonic resection } \\
\text { (4) Cystectomy } \\
\text { (5) Fresh lymph node } \\
\text { (6) Gastric carcinoma } \\
\text { (7) Head and neck resection } \\
\text { (8) Hirschsprung's biopsy } \\
\text { (9) Laryngectomy } \\
\text { (10) Limb/digital amputation } \\
\text { (11) Malignant breast lump } \\
\text { (12) Mastectomy } \\
\text { (13) Oesophagectomy } \\
\text { (14) Ovarian tumour } \\
\text { (15) Neck dissection } \\
\text { (16) Penile carcinoma } \\
\text { (17) Radical prostatectomy } \\
\text { (18) Renal tumour } \\
\text { (19) Salivary gland tumour } \\
\text { (20) Small bowel tumour } \\
\text { (21) Soft tissue tumours (large) } \\
\text { (22) Testis (neoplastic) } \\
\text { (23) Uterine carcinoma } \\
\text { (24) Whipple's resection }\end{array}$ \\
\hline
\end{tabular}

BMS, biomedical scientist; CIN, cervical intraepithelial neoplasia; TUR, transurethral resection.

\section{MATERIALS AND METHODS}

\section{BMS training and error log}

A training plan was drawn up to follow a similar path to that of a trainee pathologist. Initial training in another laboratory with experience of BMS trimming (County Antrim) was followed by in house training. A logbook was kept of specimens examined and the histology of cases was discussed, so that the BMS was aware of the reasons for block selection. There was close supervision by one pathologist until the BMS was experienced enough to handle specimens unsupervised.

Weekly slide meetings are held to discuss interesting cases and to improve the knowledge of the two BMS staff. The cases are audited as part of the 5\% audit of the general work of the department, and if specific problems are discovered during reporting, an audit sheet is completed. An error log is kept of any problems with the BMS specimen dissection. Regular meetings are also held to review progress and discuss any problems.

\section{Time spent on each specimen}

During the period 1 March 2002 to 2 April 2002 a record was kept at the trimming bench of what category of specimen was being trimmed, the start and stop times for that category, the number of specimens trimmed, and the grade of the member of staff who did the trimming (that is, BMS/trainee pathologist/consultant pathologist). Mean times for each specimen category could then be calculated for each grade of staff.

\section{Quality of specimen handling}

Each specimen protocol listed several actions to be performed (including procedures, description, and block selection). For each category B specimen trimmed in November 1997 or November 2001, it was noted whether each action had been performed, not performed, or was not applicable/not assessable. For each action of each protocol, the following data were calculated:

(1) The percentage of specimens in 1997 for which the action was performed, defined as $100 \% \times$ number of specimens on which the action was performed/(number of specimens on which the action was performed + number of specimens on which the action was not performed). Not applicable/not assessable recordings were ignored (that is, were not regarded as the action having not been performed).

(2) The percentage of specimens in 2001 for which the action was performed, defined in the same way.

(3) The corrected percentage difference, defined as (2) - (1). Therefore, a positive corrected percentage difference indicates better adherence by BMSs to that part of the protocol, whereas a negative value indicates a better adherence by pathologists. This was only calculated when values for both (1) and (2) could be obtained, and hence the average corrected percentage difference is a more accurate overall reflection of differences in protocol adherence than the difference between average values for (1) and (2) would have been.

Mean values, standard deviations, and skewness for (1), (2), and (3) were calculated using standard spreadsheet software.

Because there were only two BMSs whose work was being assessed in our study, it was considered inappropriate to 


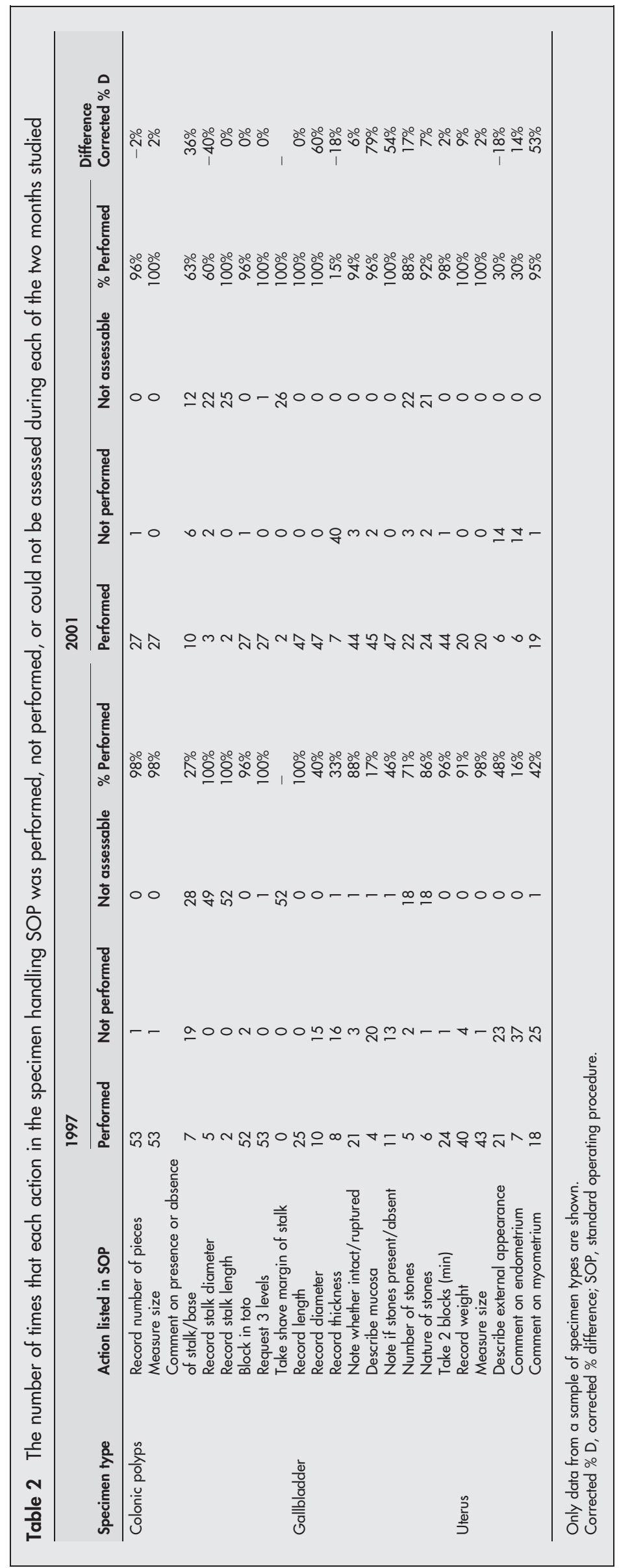

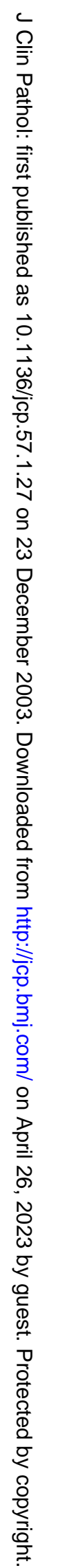




\begin{tabular}{|c|c|c|c|c|c|}
\hline & $\begin{array}{l}\text { Diagnostic } \\
\text { skin biopsy }\end{array}$ & $\begin{array}{l}\text { Skin } \\
\text { excision }\end{array}$ & $\begin{array}{l}\text { Skin shaving/ } \\
\text { cautery }\end{array}$ & Uterus & Appendix \\
\hline \multicolumn{6}{|l|}{$\begin{array}{l}\text { Extra blocks } \\
1997\end{array}$} \\
\hline Needed & 0 & 9 & 0 & 2 & 2 \\
\hline Not needed & 36 & 275 & 30 & 42 & 21 \\
\hline$\%$ Needed & $0 \%$ & $3 \%$ & $0 \%$ & $5 \%$ & $9 \%$ \\
\hline \multicolumn{6}{|l|}{2001} \\
\hline Needed & 2 & 9 & 0 & 3 & 2 \\
\hline Not Needed & 47 & 279 & 29 & 17 & 23 \\
\hline \multicolumn{6}{|l|}{$\begin{array}{l}\text { Extra levels } \\
1997\end{array}$} \\
\hline Needed & 8 & 30 & 3 & - & - \\
\hline Not needed & 28 & 254 & 27 & - & - \\
\hline $\begin{array}{l}\% \text { Needed } \\
2001\end{array}$ & $22.2 \%$ & $10.6 \%$ & $10.0 \%$ & - & - \\
\hline Needed & 7 & 52 & 0 & - & - \\
\hline Not needed & 42 & 235 & 28 & - & - \\
\hline$\%$ Needed & $14.3 \%$ & $18.1 \%$ & $0.0 \%$ & - & - \\
\hline
\end{tabular}

calculate $\mathrm{p}$ values for differences between the two months being compared.

\section{Extra blocks and levels}

A record was made of whether or not extra blocks were required and whether or not subsequent extra levels were required for appendices, benign uteri, and skin biopsies. These specimen types were chosen for assessment of extra blocks and levels because the original number of blocks taken may vary according to the assessment at the trimming bench, and because the protocols regarding initial numbers of blocks and levels have not changed between 1997 and 2001. Requirements for extra blocks were determined by examining the slides in the departmental file, extra blocks being labelled differently from initial blocks. Extra levels were defined as further levels (that is, levels excluding those requested at the trimming bench) or deeper cuts. For each of these specimen types, the numbers of specimens requiring extra blocks or requiring extra levels could then be expressed as a percentage of the total number of such specimens received in the same month.

\section{RESULTS}

\section{Time for each specimen}

Of the 1709 specimens received in March 2002, 669 were category B specimens. Of these, 518 were trimmed by BMSs, with a mean time of 110 seconds/specimen; 42 were trimmed by consultant pathologists, with a mean time of 108 seconds/ specimen. (The remainder of the category B specimens were trimmed by the trainee pathologist.)

\section{Quality of specimen handling}

Data were recorded from 672 specimens received in November 1997. From these data, for 124 different actions the percentage of specimens for which each action had been performed could be assessed, and the values ranged from $0 \%$ to $100 \%$, with a mean value of $60.2 \%$ (SD, $40.6 \%$; negatively skewed). For November 2001, this could be assessed for 134 actions (from data collected from 660 specimens) and the percentage of specimens for which a given action had been performed ranged from $0 \%$ to $100 \%$, with a mean value of 80.1\% (SD, 32.2\%; negatively skewed). For 120 actions, a corrected percentage difference could be calculated. The corrected percentage differences range from $-100 \%$ to $100 \%$, with a mean value of $17.7 \%$ (SD, 35.3\%; positively skewed).
As an example, table 2 shows the percentages of each action performed for a sample of specimen types.

\section{Extra blocks and levels}

In 1997, 3\% ( 13 of 404) of those specimens for which data on extra blocks were recorded required extra blocks; in 2001, the proportion was $1 \%$ higher, being $4 \%$ (16 of 395).

In $1997,12 \%$ (41 of 309) of those specimens for which data on extra levels were recorded required extra levels; in 2001, the proportion was $4 \%$ higher, being 16\% (59 of 305). Table 3 shows a breakdown of extra blocks and levels required by specimen type.

\section{Error log}

A review of the error log since the introduction of BMS trimming has shown only minor deviations from the protocols-for example, extra levels not asked for at the time of specimen trimming. There were two more important errors - one being a skin biopsy with two lesions, only one of which had been sampled. However, this was clear from the history and extra tissue was taken before the report was issued. The second was a hysterectomy with separate ovary and fallopian tube, the ovary was not sampled initially. In no case was an erroneous final report issued.

\section{DISCUSSION}

There is little published in the literature regarding the assessment of quality of specimen handling, and we believe that this is the first study to assess the impact of trimming by BMSs on the workload of pathologists in the UK. Here, we report a higher adherence to specimen handling protocols when BMSs trimmed than when consultant pathologists trimmed specimens. Improvements in specimen description compensate for the reporting pathologists' not having seen the specimen, and should provide the clinician with more clinically useful information in the macroscopic section of pathology reports. For example, there were more comments by BMSs than by pathologists on the nature of the cut surface of lymph nodes (data not shown), and on the presence/ absence of a stalk or base in colonic polyps specimens. Of course, not all actions in the SOPs have equal importance, so that tighter adherence to certain parts of the SOP may not necessarily impact upon the quality or accuracy of the final report. Therefore, regular audit of BMS trimming and 
revision of SOPs are required to ensure that important parts of the handling procedures are being performed.

Tighter adherence to the handling protocol has led to a more standardised method of trimming. This enables the specimens to be distributed among the pathologists within the department for reporting, rather than all specimens being reported by the pathologist who trimmed them. It has been argued that macroscopic examination and histological examination of a specimen should be performed by the same person. ${ }^{6}$ However, in many laboratories, several different pathologists may be involved in specimen handling and reporting. This may have the disadvantage that different pathologists trim in different ways, whereas in our department BMS staff trim in a standardised fashion.

Because in our department consultant pathologists now trim only a small number of category B specimens (namely those that are part of a multipart specimen, which also includes a part fitting into category $\mathrm{C}$ or D), our study was performed retrospectively. This has introduced two complicating factors. First, there may be minor changes in protocols over time. Second, because of the general improvement of quality standards resulting from the introduction of clinical governance and the new requirements for Clinical Pathology Accreditation, pathologists have a greater appreciation of the importance of adhering strictly to SOP protocol. Therefore, one may expect adherence to specimen handling protocols both by medical and by technical staff to have been higher in 2001 than in 1997. However, there are two reasons why we feel that this will have only a minimal complicating effect on our findings. First the departmental protocols in 2001 are in large the same as trimming guidelines already given in an established surgical pathological textbook in 1997, and indicate the procedures which pathologists have been taught to perform. Second, although in recent years new guidelines have been issued relating to specimen handling and reporting, they relate mainly to more complex specimens (predominantly category D specimens), rather than the more straightforward specimens that our BMSs trim. The most likely major cause of lack of adherence to guidelines is that the pathologist feels experienced enough to take "shortcuts", and this is often still the case even when the pathologist is aware of departmental SOPs.

We report almost no difference in time spent trimming category B specimen between consultant pathologists and BMSs, so that the 16 hours spent by BMSs trimming category B specimens indicates a saving of 16 hours of consultant time each month. During the month when specimen trimming times were recorded, six hours and 42 minutes of consultant time were spent trimming category $\mathrm{C}$ specimens (data not shown). This consultant time would be freed if category $\mathrm{C}$ specimens were also to be trimmed by BMSs, giving a total saving of over 22 hours of consultant time each month.

We feel that these advantages outweigh the relatively small number of extra levels and extra blocks required when BMSs trim. Our study differs from that of Galvis et al, ${ }^{7}$ who showed a lower tissue resubmission rate when trimming was performed by technical staff rather than pathologists. One possible explanation is that Galvis et al were comparing PAs with trainee pathologists, not with consultant staff. Another is that the PA is an established post, ${ }^{8}$ and there have been PAs involved in trimming since $1969,{ }^{9}$ making it likely that the PAs in their study are more experienced at trimming than the BMSs in our study. It may be that the proportion of extra levels and extra blocks will fall with time.

Our study compared the quality of trimming of only two BMSs with that of consultant staff. Although the small number of BMSs involved prevents meaningful statistical analysis, we nevertheless show that it is possible for the quality of trimming by well motivated and appropriately

\section{Take home messages}

- Biomedical scientists (BMSs) showed a higher adherence to specimen cut up protocols than did consultant pathologists

- Although a small number of extra blocks and levels are required when BMSs trim, the advantages and savings in consultant time outweigh this small disadvantage

- This practice results in a reduction in consultant pathologist workload and provides extra job satisfaction for BMSs, with no reduction in the quality of dissection

trained BMSs to be at least equal if not better than that of pathologists. Training and staff motivation (both on the part of the BMS and the training pathologist) are key to BMSs being able to trim specimens satisfactorily. In Newcastle, Australia, BMSs can usefully trim simple specimens after approximately four weeks of training, and undergo further training and assessment before handling more complex specimens. ${ }^{10}$ In the USA, there are established training programmes for PAs, ${ }^{11}$ but there is as yet no defined training programme in the UK. Draft guidelines for the involvement of BMSs in trimming are available, ${ }^{12}$ and an earlier draft of the college guidelines was consulted before the development of our in house training and review procedures.

"It is possible for the quality of trimming by well motivated and appropriately trained biomedical scientists to be at least equal if not better than that of pathologists"

Both of the BMSs who trim specimens claim to have increased job satisfaction, and this is also the experience reported by others. ${ }^{5}{ }^{10}$ There are also other benefits from closer team working because several specimen handling protocols have been amended to facilitate specimen embedding. For example, all skin excisions are now inked by the BMS. This was in place before the recent publication of the Royal College of Pathologists' minimum dataset. ${ }^{13}$ Some authors have commented that this is an unrealistic guideline, ${ }^{14}$ but inking makes it easier to embed the skin biopsies and to ensure the quality of the sections sent through to the pathologist (V McTaggart, personal experience), even for benign skin biopsies, so that one can have a high degree of confidence in assessing the completeness of excision.

Extension of the BMS role has been criticised $^{1}$ on the grounds that technical staff also face increasing workloads and time spent trimming would be time not spent on current duties. Hopefully, however, increased job satisfaction and the potential for an increased salary (with wider recognition of the skills required) would be two incentives to start a career as a BMS. This could open up an alternative career path with more clinical involvement, rather than the more traditional management career advancement.

The numbers of requests and the amount of information required in pathology reports are rising, ${ }^{15}$ further increasing pathologists' workloads. The introduction of BMS trimming has been effective in reducing the pathologists' workloads in our department and enhancing BMS morale. Alternative suggested methods of reducing workload are not to report specimens for which the report would be unlikely to influence patient management, based on clinical history and macroscopic assessment by the pathologist, ${ }^{16-19}$ and developing waiting lists. 
In conclusion, we report a higher adherence to specimen cut up protocols by BMSs than consultant pathologists, and demonstrate a reduction in consultant pathologist workload as a result of the reduced time spent at the trimming bench. These benefits have been demonstrated within three years of introducing trimming by BMSs, although the benefits were apparent much earlier. We found no decrease in the quality of specimen handling when performed by BMSs. Our findings support the introduction of BMS cut ups as an efficient use of human resources within the histopathology laboratory, following the National Health Service plan to expand the skill mix in the workforce. ${ }^{2021}$

\section{Authors' affiliations}

F R Duthie, Glasgow Royal Infirmary, 84 Castle Street, Glasgow G4 OSF, UK

E R Nairn, A W Milne, V McTaggart, D Topping, Crosshouse Hospital, Kilmarnock KA2 OBE, UK

\section{REFERENCES}

1 Ball RY. MLSOs are not doctors (letter). BMJ 1994;309:803.

2 Wright DH. Histopathology and medical laboratory scientific officers. Pathologists are responsible for diagnosis (letter). BMJ 1994;309:803-4.

3 Grzybicki DM, Reilly TL, Hart AR, et al. National practice characteristics and utilization of pathologists' assistants. Arch Pathol Lab Med 2001;125:905-12.

4 Ashworth TG. The future for histopathology: protectionism or prudence? BMJ 1994;309:417.

5 Biggart JD, Allen DC. MLSOs are efficient and save money (letter). BMJ 1994;309:803.

6 Fletcher S. Histopathology and medical laboratory scientific officers (letter). BMJ 1994;309:1513.

7 Galvis CO, Raab SS, D'Amico F, et al. Pathologists' assistants practice: a measurement of performance. Am J Clin Pathol 2001;116:816-22.
8 What is a pathologists' assistant? Available at http:// www.pathologistsassistants.org/ (accessed 3 August 2003).

9 Kutys R, Reilly T. Pathologists' assistants in the United States. The role of pathologists assistants and the American Association of Pathologists' assistants in anatomic pathology practice. ACP News. Winter 2001:5-7.

10 Zardawi I. Delegation to BMSs (letter). Bulletin of the Royal College of Pathologists 2002. October 2001;116:20.

11 Mergner WJ, Vigorito RD, Pratt PC, et al. Pathologists' assistant training programs: a report. Hum Pathol 1981;12:207-11.

12 The Royal College of Pathologists. Working Party Report. Draft guidelines for the involvement of BMSs in the dissection of specimens and selection of tissues. London: The Royal College of Pathologists, 2001 (also available at http://www.rcpath.org/resources/pdf/biomedical.pdf (accessed 3 August 2003)).

13 The Royal College of Pathologists. Minimum dataset for the histopathological reporting of common skin cancers (2002). London: The Royal College of Pathologists, 2002 (also available at http://www.rcpath.org/resources/pdf/ skincancers2802.pdf (accessed 3 August 2003)).

14 Rubin A. Skin cancer minimum dataset. Available at http:// www.doctors.net.uk/forum/index.cfm?action $=$ viewpost\&forum id $=$ 25\&post_id = 151915 (accessed August 2003).

15 Cross SS, Bull AD. Is the informational content of histopathological reports increasing? J Clin Pathol 1992;45:179-80.

16 Brooks SG, Hughes RG. Selective histopathology for appendix specimens. Lancet 1987; ii: 1456.

17 Channer JL, Jenkins M. Selective histopathology of appendix specimens. Lancet 1988;i:110-11.

18 Alun-Jones T, Hill J, Leighton SEJ, et al. Is routine histological examination of nasal polyps justified? Clin Otolaryngol 1990;3:217-19.

19 Salmon HA, Smith JHF, Balsitis M. Is microscopic assessment of macroscopically normal hysterectomy specimens necessary? J Clin Pathol 2002;55:67-8.

20 Secretary of State for Health. The NHS plan. A plan for investment. A plan for reform. London: HMSO Publications, 2000 (also available at http:// www.nhs.uk/nationalplan/ (accessed 3 August 2003)).

21 Scottish Executive Health Department. Building the workforce for NHS Scotland: response to planning together. Edinburgh: Scottish Executive Publications, 2002 (also available at http://www.scotland.gov.uk/library3/ health/ptfr.pdf (accessed August 2003)). 